\title{
CHEMICAL ACCIDENT AREA RECONNAISSANCE BY UNMANNED AIRCRAFT*
}

Dejan Indjić, Ivan Petrović, Negovan Ivanković, Djordje Djukić University of Defence in Belgrade, Military Academy

Chemical accidents, as unexpected events, occur in contemporary society relatively often, and the resulting consequences can be different - from very small to catastrophic. Within the integrated response to chemical accidents, chemical reconnaissance of the accident area takes a significant place.

This paper presents the possibility of prioritizing the criteria and attributes of the criterion for selecting unmanned aircraft for reconnaissance of the chemical accident area. By analyzing the content of the available literature, the criteria for evaluating the alternatives of the offered "miniunmanned aircraft" are set out.

This paper deals with testing using the questionnaire, processing the obtained data and prioritization of the criteria and attributes using the fuzzy AHP method and examination of the results consistency by the consistency degree. Testing of the obtained results and selection of optimal unmanned aircraft using the TOPSIS method has been carried out, as well.

Due to the extreme danger that personnel are exposed to during the chemical reconnaissance of the accident area (high concentrations of dangerous chemicals, long-term wearing of protectiveequipment, increased psychophysical stress, etc.), this paper considers the possibility of using unmanned aircraft. Furthermore, this paper suggests the way of selecting optimal UA as an element for reconnaissance in a particular chemical accident.

Key Words: chemical accident, integrated response, chemical reconnaissance, unmanned aircraft, fuzzy AHP method, TOPSIS method

\section{Introduction}

$\Delta s$ chemical substances are naturally aggressive in relation to humans and the environment, their uncontrolled release can lead to unforeseeable consequences. The risk of such accidents exists in the chemical industry, devices, installations and equipment, transport facilities and others, where chemical substances are produced,

\footnotetext{
* This paper is the result of the project VA-DH/3/17-19 "Calculation of Long-term Financial Sustainability of the Duty Forces of Air Defense System of Serbian Armed Forces in Performing the Airspace Control and Protection in Peace", funded by the Ministry of Defence of the Republic of Serbia.
} 
processed, stored, transported or otherwise use hazardous chemical substances (hereinafter TC). Chemical accidents represent a particular price for the industrial development of the modern society. Chemical accident represents the sudden, unexpected and uncontrolled release of large amounts of toxic, flammable or explosive substances into the atmosphere, watercourses and the soil, which may have a harmful effect on humans, material goods and the environment. The consequences that can arise (great human and material losses, disturbance of regular activities, environmental degradation, etc.) have imposed the need for implementing adequate measures of the integrated response to the chemical accident (Indjić et al., 2015).

One of the initial (and the most important) measures of the integrated response to the chemical accident is reconnaissance of the place where the accident occurred. In the Republic of Serbia, these tasks are mainly performed by the forces (teams) of the Sector for Emergency Management (the Ministry of Internal Affairs), the Public Health Institute (the Ministry of Health), the local government (municipalities - the city where chemical accident occurred) and the specialized units of the Serbian Armed Forces (primarily NBC units ) (Indjić, 2014).

When performing this extremely complex task, the people that are involved are at great risk due to the following specificity of chemical accident:

- extremely high concentrations of TC in the hot spot of an accident (deadly for humans);

- high temperatures and possibility of explosion - fire (depending on the type and characteristics of released TC), (Rajić et al., 2013);

- long-term wearing of protective equipment (several hours in the case of major chemical accidents), (Jovanovic et al., 2016);

- increased psychophysical stress (Karkalić et al., 2015), etc.

Bearing in mind the mentioned hazards to the humans, this paper considers the possibility of using unmanned aircraft (UA) for this task. Of course, the advantage of UA is the ability to collect 3D information from the airspace that is hardly accessible from the ground (Roca et al., 2016).

The terminology used today for non-human crews is still not completely defined. The name that has been most frequently used in the development of these devices in numerous professional publications is "Unmanned Aerial Vehicle" (UAV). In the Republic of Serbia, the term "unmanned aircraft" (UA) is most often used for this type of device, so we will use this term. This paperoffers the following definition: "Unmanned aircraft is a type of aircraft controlled by a computer that is on an aircraft or whose flight is remotely operated by an operator on the ground". (Law on Emergency Situations, 111/2009, 92/2011 and 93/2012) In order to acquaint yourself with the method of choosing UA for the performance of the task of chemical reconnaissance of the accident area, the paper presents scheme of integrated response to chemical accidents in the Republic of Serbia, UA categorization, methodology of evaluating the criteria for selecting optimum UA using the fuzzy AHP method, estimation of criteria prioritization for UA selection, as well as UA selection using scientific methods: fuzzy AHP and TOPSIS.

Having in mind the aforementioned, the research has been carried out with the overall goal: evaluation of criteria for selection of modern BV for reconnaissance of the chemical accident area by using scientific methods: fuzzy AHP and TOPSIS. 
The application of these scientific methods enables group decision- making process by taking into account the uncertainties of the evaluation of the experts, which makes the research scientifically and methodologically justified. In its essence, this procedure can be applied in any case of evaluating the criteria for the selection of various systems that can be used in emergencies, as well as when choosing a wide range of technological solutions in other spheres of social life, which makes this research practically justified.

\section{Integrated Response to Chemical Accident}

In order to perform optimum engagement of the forces of the society (chemical companies, local government, health institutions, police, army, etc.) in an integrated response to the chemical accident, it is necessary to apply the appropriate methodology in the decision-making process of selection of forces to be used in such situation (Figure 1) (Indjić, 2014).

The diagram below shows the asymmetric strategy of the integrated response to chemical accidents according to $\mathrm{O}^{3}$ methodology: discovery $-\mathrm{O}^{1}$, decide $-\mathrm{O}^{2}$, disable (enable) $-\mathrm{O}^{3}$, in relation to the NATO decision-making process in combat conditions according to $D^{3}$ methodology: Detect $-D^{1}$, Decise $-D^{2}$, Destroy $-D^{3}$ (Mučibabić, 2003; Kelemeniš, 2016).

In the NATO methodology, the focus is given on the superior technique where the goal is first detected, then the decision on optimal use is made and in the end there is the effective destruction of the chosen target.

In the Serbian Armed Forces (SAF) the term destroy is replaced with the term disable (enable), due to the restrictions that the SAF have (primarily material, technical and financial constraints). This kind of strategy prevents the enemy from achieving the goal in a certain area when using weapons of mass destruction, i.e. enabling the survival of its own units during the execution of various tasks in such complex conditions.

Considering these two methodologies of modeling the forces for integrated response to the chemical accident, we can conclude that the use of the $\mathrm{O}^{3}$ methodology is quite acceptable because chemical accidents mostly happen in peace. Therefore, the term Destroy $^{3}$ is replaced by the expression Enable ${ }^{3}$ meaning that the forces participating in the integrated response must create adequate conditions for the implementation of assigned tasks of removing the consequences of the accident.

In this paper, the focus is on the first segment of the integrated response Discovery $O^{1}$, i.e. the examination of the consequences of chemical accident. 


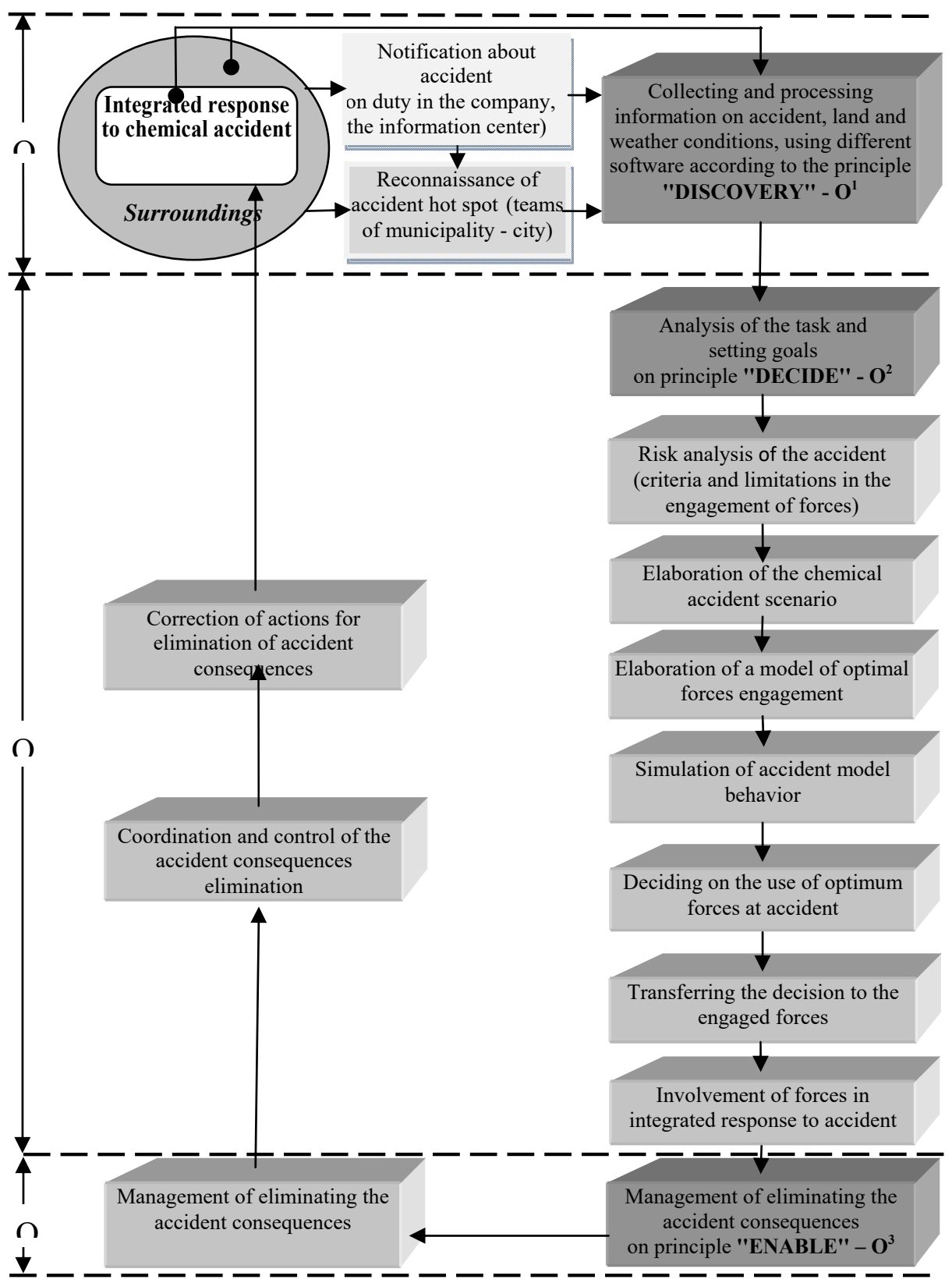

Figure 1 - Model of engaging the society forces in the integrated response to the chemical accident according to the $O^{3}$ methodology: discovery $-O^{1}$, decide $-O^{2}$, disable (enable) $-O^{3}$ (Indjić, 2014) 


\section{Categorization of Unmanned Aircraft}

In order to establish the choice of UA for the task of accident area reconnaissance, the initial parameters must be considered. If we consider UA from the same category, certain restrictions apply to: height and flight speed, range, load capacity, possibility of sensor installation (detectors), costs, etc.

In order to examine and select the optimal UA model for accident area reconnaissance, we have conducted an analysis of their classification by different methodologies, such as NATO (North Atlantic Treaty Organization), EUROCONTROL (European Organization for the Safety of Air Navigation) and UAVS (Unmanned Aerial Vehicle Systems Association).

The UA classification in the NATO Alliance is shown in Table 1.

Table 1 - Classification of UA according to NATO methodology (www.globalsecurity.org)

\begin{tabular}{|c|c|c|c|c|c|c|}
\hline Class & Category & $\begin{array}{l}\text { Level of } \\
\text { application }\end{array}$ & $\begin{array}{l}\text { Maximum } \\
\text { flight } \\
\text { altitude(ft) }\end{array}$ & $\begin{array}{c}\text { Range } \\
\text { (km) }\end{array}$ & $\begin{array}{c}\text { Basic } \\
\text { command } \\
\text { support. }\end{array}$ & Representative \\
\hline \multirow[t]{3}{*}{$\begin{array}{l}\text { Class } 1 \\
\text { (under } 150 \mathrm{~kg} \text { ) }\end{array}$} & Micro < 2kg & $\begin{array}{l}\text { Team - squad, } \\
\text { individual }\end{array}$ & $\begin{array}{l}\text { Beneath } \\
200\end{array}$ & 5 & $\begin{array}{l}\text { Team - } \\
\text { squad }\end{array}$ & Black Widow \\
\hline & Mini 2-20kg & $\begin{array}{l}\text { Unit of the } \\
\text { company level }\end{array}$ & $\begin{array}{c}\text { Beneath } \\
3000\end{array}$ & 25 & $\begin{array}{c}\text { Platoon/co } \\
\text { mpany }\end{array}$ & Raven \\
\hline & $\begin{array}{l}\text { Small > } \\
20 \mathrm{~kg}\end{array}$ & Tactical unit & $\begin{array}{l}\text { Beneath } \\
5000\end{array}$ & 50 & Battalion & Hermes 90 \\
\hline \multirow{3}{*}{$\begin{array}{l}\text { Class } 2 \\
(150 \text { до } 600 \mathrm{~kg}) \\
\text { Class } 3 \\
\text { (over } 600 \mathrm{~kg} \text { ) }\end{array}$} & Tactical & Tactical formation & $\begin{array}{c}\text { Beneath } \\
10000\end{array}$ & 200 & Brigade & Hermes 450 \\
\hline & Operative & Operative & $\begin{array}{l}\text { Beneath } \\
45000\end{array}$ & Unlimited & Staff & Predator \\
\hline & $\begin{array}{l}\text { Strategic } \\
\text { Combat }\end{array}$ & Strategic & $\begin{array}{l}\text { Beneath } \\
65000\end{array}$ & & Joint staff & Global Hawk \\
\hline
\end{tabular}

The UA classification according to the EUROCONTROL methodology is shown in Table 2.

Table 2 - Classification of UA according to EUROCONTROL methodology (www.eurocontrol.int)

\begin{tabular}{c|cccc}
\hline Class & $\begin{array}{c}\text { Maximal weight } \\
(\mathbf{k g})\end{array}$ & Range & Range $(\mathbf{k m})$ & $\begin{array}{c}\text { Maximum flight } \\
\text { altitude (ft) }\end{array}$ \\
\hline Class 0 & Under 25 & Small range & Beneath 10 & 1000 \\
Class 1 & $25-500$ & Short range & $10-100$ & 15000 \\
Class 2 & $501-2000$ & Medium range & $100-500$ & 30000 \\
Class 3 & Above 2000 & Long range & Over 500 & Over 30000 \\
\hline
\end{tabular}


According to theUAVS, UA are classified in the manner shown in Table 3.

Table 3 - Classification of UA according to UAVS methodology (Kolarek, 2010)

\begin{tabular}{|c|c|c|c|c|c|}
\hline Category name & Abbreviation & $\begin{array}{c}\text { Aircraft weight } \\
(\mathrm{kg})\end{array}$ & $\begin{array}{l}\text { Range } \\
(\mathbf{k m})\end{array}$ & $\begin{array}{l}\text { Maximum flight } \\
\text { altitude (m) }\end{array}$ & $\begin{array}{l}\text { Endurance } \\
\text { (h) }\end{array}$ \\
\hline micro & micro & $<5$ & $<10$ & 250 & 1 \\
\hline mini & $\operatorname{mini}$ & $25-150$ & $<10$ & $150-300$ & $<2$ \\
\hline small range & $\mathrm{CR}$ & $25-150$ & $10-30$ & 3000 & $2-4$ \\
\hline short range & SR & $50-250$ & $30-70$ & 3000 & $3-6$ \\
\hline medium range & MR & under 1250 & $70-200$ & 5000 & $6-10$ \\
\hline $\begin{array}{l}\text { durable medium } \\
\text { range }\end{array}$ & MRE & under 1250 & $>500$ & 8000 & $10-18$ \\
\hline $\begin{array}{l}\text { deep penetration at } \\
\text { low altitudes }\end{array}$ & LADP & under 350 & $>250$ & $50-9000$ & $0,5-1$ \\
\hline $\begin{array}{l}\text { long durability at low } \\
\text { altitudes }\end{array}$ & LALE & $<30$ & $>500$ & 3000 & $>24$ \\
\hline $\begin{array}{l}\text { durability at low } \\
\text { altitudes }\end{array}$ & MALE & under 1500 & $>500$ & 14000 & $24-48$ \\
\hline
\end{tabular}

In the Republic of Serbia, the UA flight is regulated by the Rulebook on Unmanned Aircraft. The same Rulebook has done the UA classification according to three criteria: the management mode, thepurpose and the operating mass and performance. (Rulebook on Unmanned Aircraft, 2015)

According to the management mode, UA are classifiedin the following way:

- unmanaged UA;

- automatically managed UA;

- remote controlled UA, operated by a pilot located in a station or on-board cabin.

According to the purpose UA are classified in the following way:

- UA used for economic purposes;

- UA used for non-commercial purposes (models used for scientific, educational and other purposes).

According to the operating mass and performance, UA are classified into:

- category 1 - includes UA whose operating mass is less than $0,5 \mathrm{~kg}$, with a maximum flight height of up to $50 \mathrm{~m}$, a maximum flight speed of up to $30 \mathrm{~m} / \mathrm{s}$ and a maximum range of up to $100 \mathrm{~m}$;

- category 2 - includes UA with an operating weight of $0,5 \mathrm{~kg}$ to $5 \mathrm{~kg}$, with a maximum flight height of up to $150 \mathrm{~m}$, a maximum flight speed of up to $30 \mathrm{~m} / \mathrm{s}$ and a maximum range of up to $2500 \mathrm{~m}$;

- category 3 - includes UA with an operating weight of $5 \mathrm{~kg}$ to $20 \mathrm{~kg}$, with a maximum flight height of up to $500 \mathrm{~m}$, a maximum flight speed of up to $55 \mathrm{~m} / \mathrm{s}$ and a maximum range of up to $2500 \mathrm{~m}$;

- category 4 - includes UA whose operating weight is from $20 \mathrm{~kg}$ to $150 \mathrm{~kg}$, without limitation of height, flight speed and range. 
If a particular UA in terms of the operating mass or some of the performances (flight height, flight speed or range) belongs to different categories of UA, it is considered to belong to a higher category.

Finally, Table 4 gives a review of UA categories with the examples of characteristic aircraft (systems) for each category. Ceiling (m) Autonomy (h) Range (km)

Table 4 - Overview of unmanned aircraft categories (Bento, 2008)

\begin{tabular}{|c|c|c|c|c|c|c|c|}
\hline \multirow[b]{2}{*}{ Groups } & \multirow[b]{2}{*}{$\begin{array}{l}\text { Category } \\
\text { (acronym) }\end{array}$} & \multirow[b]{2}{*}{$\begin{array}{l}\text { Maximum } \\
\text { weight }(\mathrm{kg})\end{array}$} & \multirow{2}{*}{$\begin{array}{l}\text { Maximu } \\
\text { m flight } \\
\text { altitude } \\
(\mathrm{m}) \\
\end{array}$} & \multirow{2}{*}{$\begin{array}{l}\text { Aut } \\
\text { ono } \\
\text { my } \\
\text { (h) }\end{array}$} & \multirow[b]{2}{*}{$\begin{array}{c}\text { Range } \\
(\mathrm{km})\end{array}$} & \multicolumn{2}{|c|}{ EXAMPLES } \\
\hline & & & & & & Mision & $\begin{array}{l}\text { Aircrafts } \\
\text { (systems) }\end{array}$ \\
\hline \multirow[b]{2}{*}{$\begin{array}{l}\text { Microl } \\
\text { mini }\end{array}$} & Micro & 0,10 & 250 & 1 & $<10$ & $\begin{array}{l}\text { Scouting, NBC } \\
\text { sampling, } \\
\text { surveillance inside } \\
\text { buildings }\end{array}$ & $\begin{array}{l}\text { Black Widow, MicroStar, } \\
\text { Microbat, FanCopter, } \\
\text { QuattroCopter, Mosquito, } \\
\text { Hornet, Mite }\end{array}$ \\
\hline & Mini & $<30$ & $150-300$ & $<2$ & $<10$ & $\begin{array}{l}\text { Film and broadcast } \\
\text { industries, } \\
\text { agriculture, pollution } \\
\text { measurements, } \\
\text { surveillance inside } \\
\text { buildings, } \\
\text { communications } \\
\text { relay and EW }\end{array}$ & $\begin{array}{l}\text { Mikado, Aladin, Tracker, } \\
\text { DragonEye, Raven, } \\
\text { Pointer II, Carolo } \\
\text { C40/P50, Skorpio, R-Max } \\
\text { and R-50, Robo-Copter, } \\
\text { YH-300SL }\end{array}$ \\
\hline \multirow{6}{*}{ Tactical } & $\begin{array}{l}\text { "Closed" } \\
\text { range }\end{array}$ & 150 & 3,000 & $2-4$ & $10-30$ & $\begin{array}{l}\text { RSTA, mine } \\
\text { detection, search } \\
\text { and rescue, EW }\end{array}$ & $\begin{array}{l}\text { Observer I, Phantom, } \\
\text { Copter 4, Mikado, } \\
\text { RoboCopter 300, Pointer, } \\
\text { Camcopter, Aeriel, i } \\
\text { AgriculturalRMax }\end{array}$ \\
\hline & Short range & 200 & 3,000 & $3-6$ & $30-70$ & $\begin{array}{l}\text { BDA, RSTA, EW, } \\
\text { mine detection }\end{array}$ & $\begin{array}{l}\text { Scorpi 6/30, Luna, Silver } \\
\text { Fox, EyeView, Firebird, } \\
\text { R-Max Agri / Photo, } \\
\text { Hornet, Raven, Phantom, } \\
\text { GoldenEye 100, Flyrt, } \\
\text { Neptune }\end{array}$ \\
\hline & Medium range & $150-500$ & $\begin{array}{l}3,000- \\
5,000\end{array}$ & $6-10$ & $70-200$ & $\begin{array}{l}\text { BDA, RSTA, EW, } \\
\text { mine detection, NBC } \\
\text { sampling }\end{array}$ & $\begin{array}{l}\text { Hanter B, Mücke, } \\
\text { Aerostar, Sniper, Falco, } \\
\text { Armor X7, Smart UAV, } \\
\text { UCAR, Eagle Eye+, } \\
\text { Alice, Extender, Shadow } \\
200 / 400\end{array}$ \\
\hline & Long range & - & 5.000 & $6-13$ & $\begin{array}{l}200- \\
500\end{array}$ & $\begin{array}{l}\text { RSTA, BDA, } \\
\text { communications relay }\end{array}$ & Hanter, Vigilante 502 \\
\hline & High authority & $500-1.500$ & $\begin{array}{l}5.000- \\
8.000\end{array}$ & $12-24$ & $>500$ & $\begin{array}{l}\text { BDA, RSTA, EW, } \\
\text { communications } \\
\text { relay, NBC sampling }\end{array}$ & $\begin{array}{l}\text { Aerosonde, Vulture II } \\
\text { Exp, Shadow } 600 \text {, } \\
\text { Searcher II, Hermes } \\
\text { 450S/450T/700 } \\
\end{array}$ \\
\hline & $\begin{array}{l}\text { Medium } \\
\text { height, } \\
\text { high authority }\end{array}$ & $1.000-1.500$ & $\begin{array}{l}5.000- \\
8.000\end{array}$ & $24-48$ & $>500$ & $\begin{array}{l}\text { BDA, RSTA, EW } \\
\text { weapons delivery, } \\
\text { communications } \\
\text { relay, NBC sampling }\end{array}$ & $\begin{array}{l}\text { Skyforce, Hermes } 1500, \\
\text { Heron TP,MQ-1 } \\
\text { Predator, Predator-IT, } \\
\text { Eagle-1/2, Darkstar, E- } \\
\text { Hunter, Dominator }\end{array}$ \\
\hline Strategic & $\begin{array}{l}\text { High altitude } \\
\text { and authority }\end{array}$ & $2.500-12.500$ & $\begin{array}{l}15.000- \\
20.000\end{array}$ & $24-48$ & $>2.000$ & $\begin{array}{l}\text { BDA, RSTA, EW, } \\
\text { communications } \\
\text { relay, boost phase } \\
\text { intercept launch } \\
\text { vehicle, airport } \\
\text { security }\end{array}$ & $\begin{array}{l}\text { Global Hawk, Raptor, } \\
\text { Condor, Theseus, Helios, } \\
\text { Predator B/C, Libellule, } \\
\text { EvroHawk, Mercator, } \\
\text { SenzorCraft, Global } \\
\text { Observer, Pathfinder } \\
\text { Plus }\end{array}$ \\
\hline
\end{tabular}




\begin{tabular}{|c|c|c|c|c|c|c|c|}
\hline \multirow[b]{2}{*}{ Groups } & \multirow[b]{2}{*}{$\begin{array}{c}\text { Category } \\
\text { (acronym) }\end{array}$} & \multirow[b]{2}{*}{$\begin{array}{l}\text { Maximum } \\
\text { weight (kg) }\end{array}$} & \multirow{2}{*}{$\begin{array}{l}\text { Maximu } \\
\text { m flight } \\
\text { altitude } \\
\text { (m) }\end{array}$} & \multirow{2}{*}{$\begin{array}{l}\text { Aut } \\
\text { ono } \\
\text { my } \\
\text { (h) }\end{array}$} & \multirow[b]{2}{*}{$\begin{array}{c}\text { Range } \\
(\mathrm{km})\end{array}$} & \multicolumn{2}{|c|}{ EXAMPLES } \\
\hline & & & & & & Mision & $\begin{array}{l}\text { Aircrafts } \\
\text { (systems) }\end{array}$ \\
\hline \multirow{4}{*}{$\begin{array}{l}\text { For } \\
\text { special } \\
\text { tasks }\end{array}$} & Lethal & 250 & $\begin{array}{l}3.000- \\
4.000\end{array}$ & $3-4$ & 300 & $\begin{array}{l}\text { Anti-radar, anti-ship, } \\
\text { anti-aircraft, anti- } \\
\text { infrastructure }\end{array}$ & $\begin{array}{l}\text { MALI, Harpy, Lark, } \\
\text { Marula }\end{array}$ \\
\hline & Decoys & 250 & $50-5.000$ & $<4$ & $0-500$ & $\begin{array}{l}\text { Aerial and naval } \\
\text { deception }\end{array}$ & $\begin{array}{l}\text { Flyrt, MALD, Nulka, } \\
\text { ITALD, Chukar }\end{array}$ \\
\hline & Stratospheric & TBD & $\begin{array}{l}20.000- \\
30.000\end{array}$ & $>48$ & $>2.000$ & - & Pegasys \\
\hline & $\begin{array}{l}\text { Exo- } \\
\text { stratospheric }\end{array}$ & TBD & $>30.000$ & TBD & TBD & - & MarsFlyer, MAC-1 \\
\hline
\end{tabular}

Considering the purpose of UA for reconnaissance of the accident area, the UA analysis of the "mini-unmanned aircraft" category has been carried out. In order to choose the optimal model of UA, and in accordance with the described categorizations, criteria for the selection of the optimal model of unmanned aircraft are defined.

On the basis of the collected data from the experts, the criteria for choosing the optimal UA in this paper are the following: load capacity(A), flight height (V), autonomy (S), range (D), possibility of upgrading (E), economy (F) and usage simplicity (G) (Kutnjak, 2017).

\section{Evaluation Methodology of Criteria for Unmanned Aircraft Selection}

The fuzzyAHP (Analytic Hierarchy Process) method has been used to evaluate the criteria for choosing optimal UA. In order to form an initial matrix of even comparisons, the data have been collected by the questionnaire, which was formed by Saaty in the form of nine-point scale of importance between two elements (Saaty, 1980). Prioritization, or determination of the relative weight of the elements based on their values, has been performed using the geometric mean method (Dağdeviren et al., 2009). The questionnaire was filled in by six experts, who made a comparison of the criteria. Bearing in mind the small number of experts and dispersion of the obtained values, the crisp values (the integral mean value of the received expert responses) have been processed using the triangular fuzzy number (application of one of the approaches to group decision-making).

The procedure of fuzzy process has been carried out in the following way:

The fuzzy set $\mathrm{A}$ for each real number $a$ has a value $\mu(a)$, where $\mu(a)$ is the degree of affinity $a$ for the triangular fuzzy number $A^{\prime}$ and moves in the interval $[0,1]$. In general, the fuzzy set is represented in the following way $\mathrm{A}=\{a, \mu(a)\}$.

For each crisp value $a_{i j}$ two values are assigned by which the fuzzy number is formed, and it can be displayed in the following vector form:

$a_{i j}^{\prime}=\left\{a_{i j}-\alpha, a_{i j}, a_{i j}+\alpha\right\}$, где je $1 / 2 \leq \alpha \leq 1$, where, in this case, it is equal to 0.6 (Zhu et al., 1999). 
The mentioned fuzzy number characteristics are shown in Figure 2.

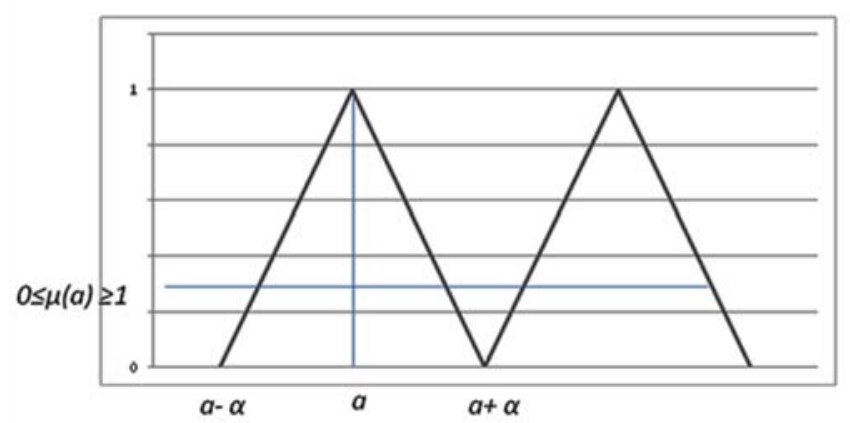

Figure 2 - Construction of the fuzzy numbers in a matrix

Bearing in mind that the calculation was performed using the geometric mean method, the rules in the work with fuzzy number are as follows:

$$
\begin{aligned}
& 1 / a_{i j}=\left\{\frac{1}{a_{i j}+\alpha}, \frac{1}{a_{i j}}, \frac{1}{a_{i j}-\alpha}\right\}, \\
& a_{1}^{\prime} \oplus a_{2}^{\prime}=\left\{a_{11}^{\prime} \oplus a_{21}^{\prime}, a_{12}^{\prime} \oplus a_{22}^{\prime}, a_{13}^{\prime} \oplus a_{23}^{\prime}\right\}, \\
& a_{1}^{\prime} \div a_{2}^{\prime}=\left\{a_{11}^{\prime} \div a_{23}^{\prime}, a_{12}^{\prime} \div a_{22}^{\prime}, a_{13}^{\prime} \div a_{21}^{\prime}\right\},
\end{aligned}
$$

where

$$
\begin{aligned}
& a_{1}^{\prime}=\left\{a_{11}^{\prime}, a_{12}^{\prime}, a_{13}^{\prime}\right\} \\
& a_{2}^{\prime}=\left\{a_{21}^{\prime}, a_{22}^{\prime}, a_{23}^{\prime}\right\}
\end{aligned}
$$

Defining fuzzy numbers into the crisp value $W$ was done as follows:

$$
w=\frac{\left(w_{11}^{\prime}, w_{12}^{\prime}, w_{13}^{\prime}\right)}{3}
$$

The consistency of all the obtained results was tested at the initial crisp value from the matrix of even comparison as follows (Pamučar, 2017):

$C R=\frac{C I}{R I}$

$C I$ - consistency index

where $C I=\frac{\lambda_{\max }-n}{n-1}$ 
$\lambda_{\max }-$ maximum own value of the comparison matrix (formula number 7 ):

$$
\begin{aligned}
& \lambda_{\max }=\frac{1}{n} \sum_{i=1}^{n} \lambda_{i} \\
& \lambda_{i}=\frac{b_{i}}{w_{i}}
\end{aligned}
$$

The value is calculated as follows (formula number 9 ):

$$
\left[\begin{array}{l}
b_{1} \\
b_{2} \\
b_{n}
\end{array}\right]=\left[\begin{array}{ll}
a_{11} a_{12} a_{1 n} \\
a_{21} a_{22} a_{2 n} \\
a_{n 1} a_{n 2} a_{n n}
\end{array}\right]\left[\begin{array}{l}
w_{1} \\
w_{2} \\
w_{n}
\end{array}\right]
$$

$R I$ - random index, which depends on the number of rows - columns of matrix $n$ (Saaty, 1980). If $C R \leq 0.10$ then the result meets the needs of the research.

After prioritization of the criteria, the optimal type of UA was selected using the TOPSIS method (four UA types were offered).

\section{Estimation of Criteria Prioritization for the Selection of Unmanned Aircraft}

On the basis of the described procedure, the initial matrix of the even comparison was formed according to the experts' response. The average matrix of the even comparison is obtained by finding medium of corresponding answer values, which were added the values of $\alpha$ and then the rule 1 was applied. In this way the procedure of fuzzy process of crisp values into triangular fuzzy numbers has been done.

Table 5 - Average matrix of even comparison

\begin{tabular}{c|ccccccc}
\hline C & $A$ & $B$ & $C$ & $D$ & $E$ & $F$ & $G$ \\
\hline A & $(1,1,1)$ & $(1.77,2.17,2.77)$ & $(0.25,0.3,0.37)$ & $(0.32,0.4,0.53)$ & $(0.27,0.32,0.39)$ & $(1.4,2,2.6)$ & $(0.73,1.33,1.93)$ \\
B & $(0.36,0.46,0.64)$ & $(1,1,1)$ & $(0.21,0.24,0.28)$ & $(0.34,0.43,0.58)$ & $(0.23,0.27,0.33)$ & $(0.9,1.5,2.1)$ & $(0.41,0.5,0.71)$ \\
C & $(2.77,3.33,3.93)$ & $(3.57,4.17,4.77)$ & $(1,1,1)$ & $(1.07,1.67,2.27)$ & $(0.73,1.33,1.93)$ & $(3.4,4,4.6)$ & $(2.23,2.83,3.43)$ \\
D & $(1.9,2.5,3.1)$ & $(1.73,2.33,2.93)$ & $(0.44,0.6,0.94)$ & $(1,1,1)$ & $(0.57,0.85,1.76)$ & $(1.9,2.5,3.1)$ & $(1.07,1.67,2.27)$ \\
E & $(2.57,3.17,3.77)$ & $(3.07,3.67,4.27)$ & $(0.52,0.75,1.36)$ & $(0.57,1.17,1.77)$ & $(1,1,1)$ & $(3.4,4,4.6)$ & $(1.4,2,2.6)$ \\
F & $(0.38,0.5,0.71)$ & $(0.48,0.67,1.11)$ & $(0.22,0.25,0.29)$ & $(0.32,0.4,0.53)$ & $(0.22,0.25,0.29)$ & $(1,1,1)$ & $(0.41,0.55,0.81)$ \\
G & $(0.52,0.75,1.36)$ & $(1.4,2,2.6)$ & $(0.29,0.35,0.45)$ & $(0.44,0.6,0.94)$ & $(0.38,0.5,0.71)$ & $(1.23,1.83,2.43)$ & $(1,1,1)$ \\
\hline
\end{tabular}


On the basis of the values of the trianaular fuzzv numbers aiven in Table 5 . the values of the relative weight coefficients in the form of the trianqular fuzzy number $w_{i}$ (Table 6) were obtained using the following formulas (Dağdeviren et al., 2009):

$$
\begin{aligned}
& w_{i 1}^{\prime}=\frac{\left(\prod_{j=1}^{n} a_{i j 1}^{\prime}\right)^{1 / n}}{\sum_{i=1}^{n}\left(\prod_{j=1}^{n} a_{i j 3}^{\prime}\right)^{1 / n}} \\
& w_{i 2}^{\prime}=\frac{\left(\prod_{j=1}^{n} a_{i j 2}^{\prime}\right)^{1 / n}}{\sum_{i=1}^{n}\left(\prod_{j=1}^{n} a_{i j 2}^{\prime}\right)^{1 / n}} \\
& w_{i 3}^{\prime}=\frac{\left(\prod_{j=1}^{n} a_{i j 3}^{\prime}\right)^{1 / n}}{\sum_{i=1}^{n}\left(\prod_{j=1}^{n} a_{i j 1}^{\prime}\right)^{1 / n}} \\
& w_{i}=\left(w_{i 1}^{\prime}, w_{i 2}^{\prime}, w_{i 3}^{\prime}\right)=\frac{\left[\left(\prod_{j=1}^{n} a_{i j 1}^{\prime}\right)^{1 / 1},\left(\prod_{j=1}^{n} a_{i j 2}^{\prime}\right)^{1 / n},\left(\prod_{j=1}^{n} a_{i j 3}^{\prime}\right)^{1 / n}\right]}{\sum_{i=1}^{n}\left[\left(\prod_{j=1}^{n} a_{i j 1}^{\prime}\right)^{1 / n},\left(\prod_{j=1}^{n} a_{i j 2}^{\prime}\right)^{1 / n},\left(\prod_{j=1}^{n} a_{i j 3}^{\prime}\right)^{1 / n}\right]}
\end{aligned}
$$

In this case $j=i=7$

The same table shows the crisn value determined bv formula 4 and the final values of the relative weights $W_{i}$ of the criteria obtained after the normalization of the crisp values.

Table 6 - Weighting coefficients for criteria

\begin{tabular}{c|cccc}
\hline$c$ & $w_{i}$ & $w_{i}$ & $W_{i}$ & Ранг \\
\hline A & $(0.06,0.1,0.16)$ & 0.11 & 0.10 & 5 \\
B & $(0.04,0.06,0.1)$ & 0.07 & 0.06 & 6 \\
C & $(0.17,0.28,0.44)$ & 0.30 & 0.27 & 1 \\
D & $(0.1,0.17,0.31)$ & 0.19 & 0.18 & 3 \\
E & $(0.13,0.23,0.38)$ & 0.25 & 0.23 & 2 \\
F & $(0.04,0.06,0.1)$ & 0.06 & 0.06 & 7 \\
G & $(0.06,0.1,0.18)$ & 0.11 & 0.11 & 4 \\
\hline
\end{tabular}


Based on the formula 7 , we get $\lambda_{\max }=7.12$ and $C I=0.02$. For $n=7 \Rightarrow R I=1.35$ (Saaty, 1980). Using formula 5 , value $C R=0.01$ was obtained, which is less than 0.1 . Based on the abovementioned, it has been concluded that the results are consistent (the experts are consistent in the even comparison of the criteria significance).

\section{Selection of Optimal Unmanned Aircraft}

After the prioritization of the criteria, the optimal type of unmanned aircraft was selected using TOPSIS method (Technique for Order of Preference by Similarity to Ideal Solution) (Hwang and Yoon, 1981). This method is based on ranking alternatives in relation to the ideal and negative ideal solution. The ideal solution maximizes the criteria of benefit type and minimizes criteria of cost type, while the negative ideal solution maximizes criteria of cost type and minimizes the criteria of benefit type. The offered alternatives are ranked on the basis of distance from the ideal solution.

The optimal alternative, in the Euclidean sense, is the one closest to the ideal and the farthest from the negative ideal alternative (Srđević et al., 2002).

The first step in applying the TOPSIS method is the formation of a quantitative initial decision - making matrix, and then the normalization of the matrix value is carried out as follows (Pamučar, 2017):

$$
\begin{aligned}
& x_{i j}=\sqrt{\sum_{i=1}^{n} r_{i j}^{2}} \text { for elements of matrix that belong to criteria of benefit type, } \\
& x_{i j}=1-\sqrt{\sum_{i j} / r_{i j}^{2}} \text { for elements of matrix that belong to criteria of cost type. (14) }
\end{aligned}
$$

In the next step, the multiplication of the normalized matrix values with values of the relative weight of the criteria is carried out:

$v_{i j}=x_{i j} w_{j} ; i=1,2, \ldots n, n$ - number of alternatives; $j=1,2, \ldots m, m$ - number of criteria (15)

Based on previous relations, a new weighted normalized matrix with elements is obtained.

The ideal solution is the following vector (Hwang and Yoon, 1981):

$$
A^{*}=\left\{\left(\max v_{i j}, j \in G\right),\left(\min v_{i j}, j \in G^{-}\right)\right\}=\left\{v_{1}^{*}, v_{2}^{*}, . . v_{m}^{*}\right\} \text {. }
$$


Negative ideal solution represents the following vector:

$$
\begin{aligned}
& A^{-}=\left\{\left(\min v_{i j}, j \in G\right),\left(\max v_{i j}, j \in G^{-}\right)\right\}=\left\{v_{1}^{-}, v_{2}^{-}, . . v_{m}^{-}\right\} . \\
& G \text { - criteria which are maximizing, } \\
& G^{-} \text {- criteria which are minimizing. }
\end{aligned}
$$

In the next step, the distance of alternatives from the ideal are determined using the following formula (Hwang and Yoon, 1981):

$$
\begin{aligned}
& S_{i}^{*}=\sqrt{\sum_{j=1}^{m}\left(v_{i j}-v_{j}^{*}\right)^{2}}, i=1, \ldots, n \\
& S_{i}^{-}=\sqrt{\sum_{j=1}^{m}\left(v_{i j}-v_{j}^{-}\right)^{2}}, i=1, \ldots, n
\end{aligned}
$$

In the next step, for each alternative, relative closeness to the ideal solution is determined (Hwang and Yoon, 1981):

$$
Q_{i}^{*}=S_{i}^{-} /\left(S_{i}^{*}+S_{i}^{-}\right), 0 \leq Q_{i}^{*} \leq 1
$$

\begin{tabular}{|c|c|c|c|c|c|c|c|c|}
\hline 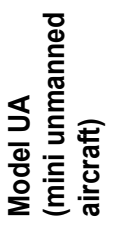 & 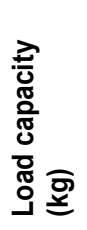 & 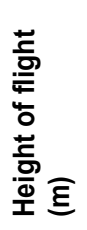 & 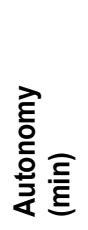 & 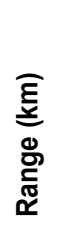 & 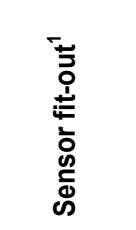 & 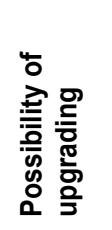 & 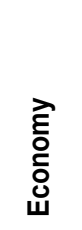 & 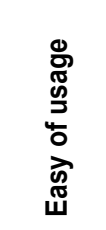 \\
\hline Model 1 & 1 & 50 & 10 & 0,1 & 1 camera & small & $60 \$$ & easy \\
\hline Model 2 & 1 & 200 & 10 & 0,5 & 1 camera & no & $50 \$$ & easy \\
\hline Model 3 & 2 & 6000 & 25 & 2 & 1 camera & medium & $300 \$$ & medium \\
\hline Model 4 & 2 & 6000 & 30 & 5 & 1 camera & high & $400 \$$ & medium \\
\hline
\end{tabular}

In the last step, alternatives areranked. The optimal alternative is the one that has the highest value $Q_{i}^{*}$ (Hwang and Yoon, 1981).

In this paper, optimal UA is selected from four offered alternatives, as shown in Table 7.

Table 7 - Characteristics of offered alternatives to unmanned aircraft

${ }^{1}$ Since each unmanned aircraft has a built-in camera (at least one), it is not taken as a criterion for selection of unmanned aircraft. 
Quantitative and qualitative characteristics of UA are given by the manufacturer. The possibility of upgrading and ease of usage represent qualitative characteristics that are arranged using the Likert scale (Table 8).

Table 8 - Likert scale for alternatives evaluation

\begin{tabular}{c|cccc}
\hline No & $\begin{array}{c}\text { Linguistic } \\
\text { designation }\end{array}$ & $\begin{array}{c}\text { Numerical } \\
\text { value }\end{array}$ & $\begin{array}{c}\text { Possibility of } \\
\text { upgrading }\end{array}$ & $\begin{array}{c}\text { Ease of } \\
\text { usage }\end{array}$ \\
\hline 1. & Very good (VG) & 5 & High & Easy \\
2. & Good (G & 4 & - & - \\
3. & Medium(M) & 3 & Medium & Moderately \\
4. & Bad (B) & 2 & Small & - \\
5. & Very bad (VB) & 1 & - & Complex \\
\hline
\end{tabular}

Based on the data in Tables 7 and 8, a quantitative initial matrix of decision is formed (Table 9).

Table 9 - Quantitative initial matrix of decision

\begin{tabular}{c|ccccccc}
\hline Type & $\mathbf{A}$ & $\mathbf{B}$ & $\mathbf{C}$ & $\mathbf{D}$ & $\mathbf{E}$ & $\mathbf{F}$ & $\mathbf{G}$ \\
& $\mathbf{0 . 1 0}$ & $\mathbf{0 . 0 6}$ & $\mathbf{0 . 2 7}$ & $\mathbf{0 . 1 8}$ & $\mathbf{0 . 2 3}$ & $\mathbf{0 . 0 6}$ & $\mathbf{0 . 1 1}$ \\
\hline A1 & 1 & 50 & 10 & 0,1 & 2 & 60 & 5 \\
A2 & 1 & 200 & 10 & 0,5 & 1 & 50 & 5 \\
A3 & 2 & 6000 & 25 & 2 & 3 & 300 & 3 \\
A4 & 2 & 6000 & 30 & 5 & 5 & 400 & 3 \\
Criterion & max & max & max & max & max & min & max \\
\hline
\end{tabular}

After normalizing values (Formula 14), a weighted normalized matrix was obtained using formula 15 (Table 10).

Table 10 - Weighted normalized matrix of decision

\begin{tabular}{c|ccccccc}
\hline Type & $A$ & $B$ & $C$ & $D$ & $E$ & $F$ & $G$ \\
\hline A1 & 0.032 & 0.000 & 0.065 & 0.003 & 0.074 & 0.053 & 0.067 \\
A2 & 0.032 & 0.001 & 0.065 & 0.017 & 0.037 & 0.054 & 0.067 \\
A3 & 0.063 & 0.042 & 0.163 & 0.067 & 0.110 & 0.024 & 0.040 \\
A4 & 0.063 & 0.042 & 0.195 & 0.166 & 0.184 & 0.013 & 0.040 \\
\hline
\end{tabular}

Ideal solution is:

$$
A^{*}=\{0.063,0.042,0.195,0.166,0.184,0.013,0.067\}
$$


Negative ideal solution is:

$$
A^{-}=\{0.032,0,0.065,0.003,0.037,0.054,0.04\} \text {. }
$$

Using the formulas 16 and 17, the Euclidean distances of alternatives to the ideal and negative ideal solution were obtained (Table 11).

Table 11 - Euclidean distance of the alternatives

\begin{tabular}{c|cc}
\hline Type & $S_{i}^{*}$ & $S_{i}^{-}$ \\
\hline A1 & 0.24514 & 0.04549 \\
A2 & 0.25580 & 0.02983 \\
A3 & 0.13153 & 0.15026 \\
A4 & 0.02668 & 0.26398 \\
\hline
\end{tabular}

The relative proximity of alternatives to the ideal solution is calculated by using formula 18, and then the ranking of the alternatives has been performed (Table 12).

Table 12 - Ranking of alternatives

\begin{tabular}{c|cc}
\hline Type & $Q^{*}$ & Rank \\
\hline A1 & 0.15653 & 3 \\
A2 & 0.10444 & 4 \\
A3 & 0.53324 & 2 \\
A4 & 0.90820 & 1 \\
\hline
\end{tabular}

\section{Discussion}

On the basis of the obtained results, the optimal variant is the A4 (the unmanned aircraft model 4). Of course, it is necessary to install a modern sensor or a chemical detector on the selected UA, by which we will determine the type and quantity of TC, the spread direction of the contaminated cloud, certain meteorological parameters, etc.

The best example for this is the National Aeronautics and Space Administration (NASA), which developed a sensor that is easily converted to a chemical detector by simply connecting it to the "iPhone". According to the producer, currently this sensor successfully detects the presence of ammonia, chlorine and methane (Kutnjak, 2017). 
The chip used for detection is made of silicone. It is extremely small in size (the size of a postage stamp) and can easily be installed on unmanned aircraft. In addition to detection, the chip is equipped with an alarm that informs the user of the danger (Hsu, 2009).

Due to its small dimensions, it does not represent load during installation on a particular UA, and in the subsequent period the focus is on increasing the number of TCs that the chip can detect.

The idea is that the massive use of these and similar detectors increases the security of the population, and that the authorities responsible for responding in crisis situations provide quick information about the site, the time of the accident, the type of contaminant, etc. The existence of such devices will significantly improve the system of response to the crisis caused by chemical accidents, i.e. to facilitate the work of teams in the integrated response to the accident.

Furthermore, modern UA can be equipped with sensors that can provide precise information about the weather conditions of interest to the end user. In this way, it is possible to quickly obtain the necessary data for the assessment of the consequences and information on the degree of ecological vulnerability of the area, where the chemical accident occurred (Gaston and Anderson, 2013).

The prioritization of the criteria and attributes of the criteria for the selection of UA for the reconnaissance of the accident area, has not been the subject of the scientific research so far. To some knowledge, the evaluation of criteria and attributes (total of 7 criteria) using the AHP method is carried out (Kutnjak, 2017). According to its results, the most important criterion is "autonomy" with a relative weight of 0.244 , while the least important criterion is "economy" with a relative weight of 0.054 . In this research prioritization has also been done for seven criteria (load $-A$, height of the flight $-V$, autonomy $-S$, range $-D$, possibility of upgrading $-E$, economy $-F$ and ease of usage $-G$ ).

In this paper, the most important criterion is "autonomy", while the least important criteria are "height of the flight" and "economy".

Prioritization has been done using the fuzzy AHP method, which is one of the group decision-making tools, where the number of respondents is small (in this case six). It is also necessary to emphasize that the paper refers to the need for prioritization of the criteria for the selection of UA for reconnaissance of the chemical accident area from the point of view of use in peace (chemical accidents can also occur in combat conditions). The criteria for selection of UA are the following: autonomy -0.27 , possibility of upgrading -0.23 , range -0.18 , ease of use -0.11 , load capacity -0.10 , height of the flight -0.06 and economy -0.06 .

On the basis of the results of the research, it can be concluded that the experts, nevertheless, consider that the "autonomy" and the "possibility of upgrading" UA (hardware and software components) have a major influence on the selection and application of UA (bearing in mind the work of UA over a long period of time and different types of built-in sensors). It is also interesting to note that greater significance is given to "range" of UA than to "simplicity of use" and "load capacity", while "flight height" and "economy" are the last. It is obvious that the experts consider that the tendency for the acquisition of UA for the reconnaissance of the accident area is to be focused on the procurement of aircraft that can operate independently and with as many built-in sensors (for collecting data about TCs, meteorological conditions, monitoring of contamination, 
etc.), which would protect the people engaged in the integrated response to the chemical accident and at the same time reduce the impact of TCs. A possible explanation for the small significance of "ease of usage" and "load capacity" is that the management of UA is carried out by trained service personnel and this is a category of "mini-unmanned aircraft" that normally carries very small load. The explanation for the significance of the "height of the flight" criterion would be relatively quickly falling to the ground in case of chemical accident, even when they are carried by wind (and even then they do not go to high altitudes because they are exposed to terrestrial currents). Regarding the criteria "economy", it is at the last place considering the scope of possible consequences for people, material goods and the environment.

By the precise implementation of the scientific method TOPSIS we have obtained the following order of alternatives, i.e. the UA models from the category "mini unmanned aircraft".

- A4 (fourth alternative) - 0.90820 (1st in ranking),

- A3 (third alternative) - 0.53324 (2nd in ranking),

- A1 (first alternative) - 0.15653 (3rd in ranking),

- A2 (second alternative) -0.10444 (4th in ranking).

From this we can conclude that the fourth alternative, model 4 , has the highest total value $(0.90820)$, so it is the most favorable (optimal). This UA model is quite acceptable because it meets the most important criteria for choosing UA, which are "autonomy", "upgradability" and "range" and it has the best results compared to other considered UA models.

The next alternative is UA model 3 (best in terms of "height of the flight" and "load capacity"), then UA model 1 (best according to "ease of usage" criterion) and finally UA model 2 (best according to "economy" criterion).

On the basis of the results of the research it can be concluded that the aim of the research is completely fulfilled. The proposed model can be improved by applying more fully-qualified, modified methods of multi-criteria decision-making.

\section{Conclusion}

The paper discusses the possibility of using UA for reconnaissance of the chemical accident area within the integrated response of the state (society) to the accident situation. The choice of optimal UA for use in a particular chemical accident is shown on the basis of the criteria defined by the experts in the subject area.

After a comprehensive analysis, it can be concluded that for the needs of reconnaissance of the chemical accident area UA can be efficiently used.

The use of UA as an element for reconnaissance, within the integrated response to the accident, has many advantages:

- UA can be used in the contaminated environment without fear of the TC effects on persons, who collect data on the substance that caused the chemical accident,

- UA can carry a sensor for measuring a wide range of parameters that can be entered into the responsive monitoring software for prediction of the spread of the contaminated zone. In addition to using the most modern sensors for research, it is 
important to emphasize minimizing costs and maximizing simplicity for the purpose of different parameters monitoring (Valavanis and Vachtsevanos, 2014),

- UA can carry modern optoelectronic devices, thermal and 3D cameras, as well as other devices for operation in different exploitation conditions,

- monitoring measured parameters changes in order to make estimating the spread of the contaminated clouds faster and more realistic, so the design of the contaminated zone spread and the time for making the decision to take concrete measures is much better and faster.

The selection of optimum UA for reconnaissance of the chemical accident area within the integrated response to accident situation is presented in the final part of the paper, based on defined criteria and using the FUZZY - AHP and TOPSIS methods.

In this way, we have demonstrated one of the ways to choose the optimum UA for the needs of reconnaissance of the chemical accident area, of course with the previous upgrading of a particular sensor or chemical detector to UA (a means by which we will determine the type and amount of TC, the meteorological parameters, direction of the spread of the contaminated cloud, etc.).

In further studies, it is necessary to verify the results stated in the paper through practical research in real-life conditions (on the ground), where the results obtained by mathematical models using the unmanned aircraft would be checked in practice. With regard to this, it should develop and optimize the number of UA, which participate in the realization of $\mathrm{O}^{1}$ phase and overflow their performance in $\mathrm{O}^{2}$ phase.

\section{References}

[1] Bento, M. (2008), "Unmanned Aerial Vehicles: An Overview", working paper, Inside GNSS, january/february, pp. 54-61.

[2] Dağdeviren, M, Yavuz, S. and Kılınç, N. (2009), "Weapon selection using the AHP and TOPSIS methods under fuzzy environment", Expert Systems with Applications, Vol. 36 No. 4, pp. 8143-8151.

[3] Gaston, K. and Anderson, K. (2013), "Lightweight unmanned aerial vehicles will revolutionize spatial ecology", Frontiers in Ecology and the Environment, Vol. 1 No. 3, pp. 138-146

[4] Hsu, J. (2009), "NASA Scientist Converts iPhone into Chemical Sniffer", available at: https://www.popsci.com/technology/article/2009-11/nasa-scientist-converts-iphone-chemicalsniffer (accessed 21 December 2017).

[5] http://www.globalsecurity.org

[6] https://www.eurocontrol.int

[7] Hwang, C. and Yoon, K. (1981), Multiple attribute decision making: methods and applications, Springer, Berlin

[8] Indjić, D. (2014), Model of engagement of NBC units on the elimination of consequences of a chemical accident - PhD thesis, Military Academy, University of Defense, Belgrade

[9] Indjić, D., Terzić M., Zigić S. and Rutić S. (2015), "Engagement of the Serbian Army in helping civilians in the event of nuclear and chemical accidents", Military Technical Courier, Vol. 63 No. 3, pp. 215-239

[10] Jovanović, D., Stojisavljević, P., Cvetanović, S., Rajić, D., Karkalić, R., Ivanković, N. and Senić, Z. (2016), "Testing of the functional garments with microencapsulated phase-change material in simulated high temperature conditions", Chemical Industry, Vol. 70 No. 5, pp. 573-579 
[11] Karkalić, R. Jovanović, D., Radaković, S., Rajić, D., Petrović, B., Ivanković, N. and Senić, Z. (2015), "The influence of the passive evaporative cooling vest on a chemical industry worker physiological strain level in hot conditions", Chemical Industry, Vol. 69 No. 6, pp. 587-594.

[12] Kolarek, M. (2010), "Unmanned aerial vehicles for photogrammetry", Ekscentar, No. 12, pp. 70-73.

[13] Kelemeniš, K. (2016), Political dimension of crisis management - PhD thesis, Faculty of Political Science, University of Belgrade, Belgrade

[14] Kutnjak, D. (2017), Possibilities of using unmanned aerial vehicles in chemical accident area reconnaissance - MSc work, Military Academy, University of Defense, Belgrade

[15] Law on Emergency Situations (2009), "Official Gazette of the Republic of Serbia", No. $111 / 2009,92 / 2011$ and $93 / 2012$

[16] Mučibabić, S. (2003), Decision-making in conflict situations, Vojnoizdavački zavod, Belgrade

[17] Pamučar, D. (2017), Operational research, Rabek, Belgrade

[18] Rajić, D., Kamberović, Z., Karkalić, R., Ivanković, N. and Senić, Y. (2013), "Thermal resistance testing of standard and protective filtering military garment on the burning napalm mixture", Chemical Industry, Vol. 67 No. 6, pp. 941-950

[19] Roca, D., Martínez-Sánchez, J., Lagüela, S. and Arias, P. (2016), "Novel Aerial 3D Mapping System Based on UAV Platforms and 2D Laser Scanners", Journal of Sensors, Vol. 2016, Article ID 4158370, pp. 1-8 $108 / 2015$

[20] Rulebook on Unmanned Aircrafts (2015.) "Official Gazette of the Republic of Serbia", No.

[21] Saaty, T. (1980), The analytic hierarchy process, McGraw-Hill, New York

[22] Srdjević, B., Srdjević, Z. and Zoranović, T. (2002), "PROMETHEE, TOPSIS and CP in multi-criteria decision-making in agriculture", Chronicle of Scientific Papers, Vol. 26 No. 1, pp. 5-23

[23] Valavanis, K. and Vachtsevanos, G. (2015), Handbook of Unmanned Aerial Vehicles, Springer Publishing Company, New Delhi

[24] Zhu, K.-J., Jing, Y. and Chang, D.-Y. (1999), "A discussion on extent analysis method and applications of fuzzy", European Journal of Operational Research, Vol. 116, pp. 450-456 